BMJ Open Sport \& Exercise Medicine

\title{
Prevalence and burden of overuse injuries in elite junior handball
}

\author{
Christer Aasheim, ${ }^{1}$ Håvard Stavenes, ${ }^{1}$ Stig Haugsbø Andersson, ${ }^{2}$ \\ Lars Engbretsen, ${ }^{1,2}$ Benjamin Clarsen ${ }^{2}$
}

To cite: Aasheim C, Stavenes $\mathrm{H}$, Andersson $\mathrm{SH}$, et al. Prevalence and burden of overuse injuries in elite junior handball. $B M J$ Open Sport \& Exercise Medicine 2018;4:e000391. doi:10.1136/ bmjsem-2018-000391

CA and HS contributed equally.

CA and HS are joint first authors.

Accepted 31 May 2018
Check for updates

${ }^{1}$ Department of Orthopaedics (ORTHO), Faculty of Medicine, University of Oslo, Oslo, Norway ${ }^{2}$ Oslo Sports Trauma Research Center, Department of Sports Medicine, Norwegian School of Sport Sciences, Oslo, Norway

Correspondence to Christer Aasheim; christer aasheim@hotmail.com

\section{ABSTRACT}

Aim To record overuse injuries among male junior handball players throughout a handball season.

Design Prospective cohort study.

Methods Ten Norwegian junior male handball teams (145 players aged 16-18 years) were followed for one 10-month season. All players were sent the 0slo Sports Trauma Research Center Overuse Injury Questionaire every second week to record overuse injuries located in the shoulder, elbow, lower back and knee. The relative burden of overuse injuries was calculated in each anatomical area represented, defined as the proportion of the total cumulative severity score.

Results The average prevalence of all overuse injury problems was $39 \%$ (95\% Cl $29 \%$ to $49 \%$ ) across all anatomical areas. The average prevalence of substantial overuse injury problems, defined as those leading to moderate or large reductions in training volume or sports performance, or to complete inability to participate, was $15 \%(95 \% \mathrm{Cl} 13 \%$ to $17 \%)$. Over the duration of the study, the cumulative incidence of overuse injury problems was $91 \%$ (133 players). Shoulder problems were the most prevalent (average prevalence $17 \%, 95 \% \mathrm{Cl} 16 \%$ to $19 \%$ ), whereas knee problems had the greatest relative burden. Conclusion Overuse injuries, particularly in the shoulder and knee, have a substantial impact on junior handball players' training participation and performance. Interventions to prevent overuse injuries among male junior handball players should focus on these areas.

\section{INTRODUCTION}

Handball is a sport characterised by repetitive throwing, cutting, jumping and landing, as well as frequent physical contact between players. A high injury risk has been well documented among players of all levels. For example, the IOC injury and illness surveillance system rates handball among the Olympic sports with the highest injury rate. ${ }^{1-3}$ Similarly, prospective cohort studies have demonstrated high rates of both acute traumatic injuries $^{4-10}$ and overuse injuries ${ }^{6-9}$ among senior elite players. These studies have found that the most common sites of acute injury are the ankle and the knee, ${ }^{4-10}$ whereas overuse injuries are most common in the shoulder, the knee and the lower back. ${ }^{6-9} 1112$
Impact on clinical practice

Our results reiterate the importance of preventative measures in the sport of handball and shed new light on the burden of overuse injuries among male junior handball players.

\section{What are the new findings?}

- Overuse injuries are highly prevalent among male junior handball players.

- The shoulder and knee are the most prevalent sites of overuse injuries in male junior handball players.

- Future prevention studies should focus on these areas.

Overuse injuries, which are caused by cumulative tissue overload without any clear onset, are thought to be a particular problem among young elite athletes due to rapid increases in training load, growth and musculoskeletal immaturity. ${ }^{513}$ This is of concern in handball, where elite junior players often belong to several different teams and play at both a junior and a senior level.

Epidemiological studies of junior handball players have suggested that the rate of overuse injury is high. ${ }^{11121415}$ However, these studies have used injury definitions and outcome measures best suited to recording acute injuries and are likely to have underestimated the full extent of overuse injuries. ${ }^{4}$

The Oslo Sports Trauma Research Center Overuse Injury Questionnaire (OSTRC-O) was developed to record overuse injury symptoms and their consequences on sports participation, training volume and performance. ${ }^{6}$ It has been used in prospective studies of overuse injuries in a range of sporting cohorts including elite, senior handball players. ${ }^{68916}$ However, the approach has not yet been applied to elite junior players.

The aim of this study was to use the OSTRC-O to record the prevalence of overuse injuries in four anatomical areas-the knee, shoulder, elbow and lower back_-among male 


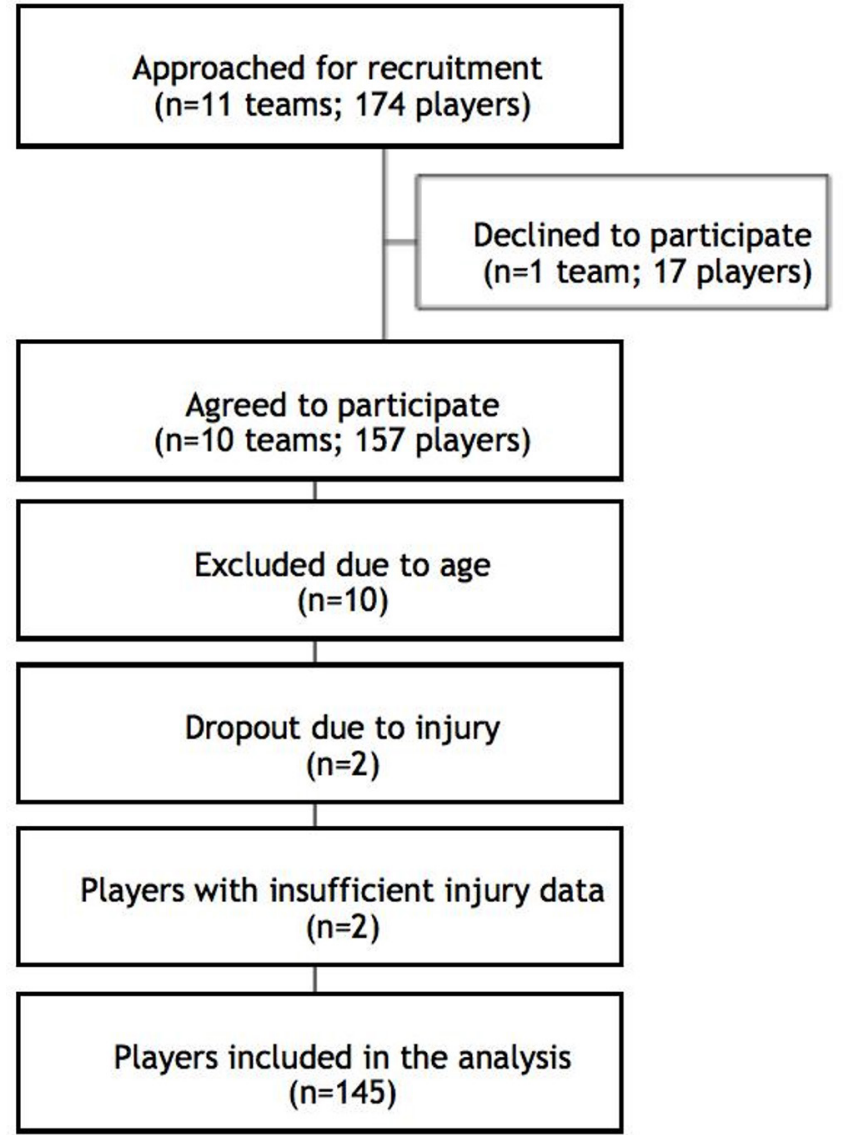

Figure 1 Study flow chart showing the recruitment, dropout and the players included.

elite junior handball players throughout an entire season. There is currently little information on this cohort in the literature, and findings from this study will help inform the development of prevention interventions.

\section{MATERIALS AND METHODS} Inclusion

This was a 34-week prospective cohort study involving junior male handball players (aged 16-18 years) in South-Eastern Norway during the 2016-2017 season. A total of 11 teams were invited to participate in the study, and 10 teams $(n=157)$ agreed to participate (figure 1$)$. The teams were a convenience sample based on their geographical location, and defined as elite level based on their results from a youth Norwegian championship series the previous season. All included teams play in regional series consisting of six to eight teams from three Norwegian counties, and most also participate in an elite nationwide weekend series. Furthermore, a large proportion of players also compete in regional or nationwide series at a senior level.

In September 2016, we visited each team during a training or match session and invited every player to participate in the study. Participation was voluntary, and all players and coaches received oral and written information about the study's aims and procedures. Written consent was obtained from all players agreeing to participate, or their guardians $(n=145)$.

\section{Baseline questionnaires}

Each player completed a baseline questionnaire containing questions about their height, weight, playing position, dominant jumping leg and throwing arm, numbers of years playing handball, whether they were a member of the national junior handball team, and how many teams in the club they represented. Players were also asked whether they had experienced shoulder, elbow, knee and/or lumbar spine problems during the previous season, and whether they had any current or long-term injuries that prevented them from participating in normal handball activity.

\section{Injury registration}

To record injuries, the OSTRC-O was distributed to all players every second Sunday from September 2016 to April 2017, 16 times in total. The questionnaire consists of four questions per anatomical area on the consequences of overuse injury on sports participation, training volume and sports performance, as well as pain (shown for the knee in figure 2). These four questions were repeated for the dominant and non-dominant shoulder, the dominant and non-dominant elbow, the dominant and non-dominant knee, and the low back. The questionnaire also recorded the number of hours of handball training, strength training and alternative training, and the number of match minutes completed in the previous 2 weeks.

Online survey software (SurveyXact V.8.2, Rambøll Management Consulting, Oslo, Norway) was used to distribute the questionnaire to players by email. The software automatically sent a reminder to non-responders each day for 3 days, using a combination of emails and short messaging service. We revisited all teams in December 2016 to encourage players to respond to every survey, and were in regular contact with coaches in order to maximise the response rate.figure 2 (Approximately here)

\section{Outcome measures}

Players were defined as having an overuse problem in a particular anatomical area if they recorded any reduced handball participation, training volume or performance, or pain. They were defined as having a substantial overuse problem if they reported moderate or severe reductions in training volume or in performance, or complete inability to participate in handball. ${ }^{6}$

Each week, we calculated the prevalence of all overuse problems and substantial overuse problems for each anatomical area by dividing the number of players reporting problems by the number of questionnaire respondents. This was monitored throughout the season, and at the end of the study we calculated the average prevalence of all problems and substantial problems in each area, as well as the $95 \%$ CI. Data collected in the first 


\section{Part 1: Knee Problems}

Please answer all questions regardless of whether or not you have problems with your knees. Select the alternative that is most appropriate for you, and in the case that you are unsure, try to give an answer as best you can anyway.

The term "knee problems" refers to pain, ache, stiffness, swelling, instability/giving way, locking or other complaints related to one or both knees.

\section{Question 1}

Have you had any difficulties participating in normal training and competition due to knee problems during the past week?

Full participation without knee problems

Full participation, but with knee problems

Reduced participation due to knee problems

Cannot participate due to knee problems

\section{Question 2}

To what extent have you reduced you training volume due to knee problems during the past week?

No reduction

To a minor extent

To a moderate extent

To a major extent

Cannot participate at all

\section{Question 3}

To what extent have knee problems affected your performance during the past week?

No effect

To a minor extent

To a moderate extent

To a major extent

Cannot participate at all

\section{Question 4}

To what extent have you experienced knee pain related to your sport during the past week?

No pain

Mild pain

Moderate pain

Severe pain

Figure 2 Oslo Sports Trauma Research Center Overuse Injury Questionnaire, knee example.

week were not included in the summary measures, as per previous recommendations. ${ }^{6}$

Additionally, we calculated a severity score from 0 to 100 for each anatomical area for every questionnaire response, using previously described methods. ${ }^{6}$

At the end of the study, all severity scores were summed in each area in order to reflect the relative burden of overuse injuries as the proportion of the total severity score in each area represented. ${ }^{17}$

\section{Statistical methods}

When comparing average prevalence measures, statistical significance $(\alpha=0.05)$ was assumed if the $95 \%$ CIs did not overlap.

In order to determine whether players who were injured at baseline were more or less likely to respond to the questionnaires, logistic regression analyses were performed, using symptoms of injury at baseline as an independent variable and a $100 \%$ response rate as a dependent variable.

\section{RESULTS}

\section{Participants}

Sixty-one per cent of the sample was 17 years old, 33\% 18 years old and $6 \% 16$ years old. Eighty-nine per cent of the cohort was right-handed and $88 \%$ used their left leg as their dominant jumping leg. Fifty-five per cent of the players participated on two different teams (senior/junior) $(n=80), 28 \%$ on one team $(n=41)$ and $17 \%$ on three teams $(\mathrm{n}=24)$. Fourteen $(10 \%)$ players were currently playing for the junior national team. The average player height was $184 \mathrm{~cm}$ tall (SD 7, range: 172-198 cm) and weighed $80 \mathrm{~kg}$ (SD 11, range: 60-115 $\mathrm{kg}$ ), and had been playing handball for 9 years (SD 2, range: $4-14$ years).

\section{Pain and injuries at baseline}

Twenty players (14\%) reported that an overuse problem in the shoulder, elbow, knee or low back areas affected their current participation in handball training or matches at baseline.

\section{Handball exposure}

The median weekly amount of training performed during the study was 14 hours. This consisted of approximately 6 hours of handball training, 4.5 hours of strength training, 3 hours of alternative training and $30 \mathrm{~min}$ of handball match play (range: 0-200 min).

\section{Response rate}

The overall response rate to the OSTRC-O was $78 \%$ and complete data were collected from $48 \%$ of the players. Sixty-eight per cent of the sample completed 12 questionnaires or more. No associations were identified between players' baseline injury status and their overall response rate.

\section{Prevalence of overuse injuries}

The average prevalence of all overuse injury problems across all anatomical areas was 39\% (95\% CI 29\% to $49 \%)$. The average prevalence of all substantial overuse injury problems across all anatomical areas was 15\% (95\% CI $13 \%$ to $17 \%$ ), and the highest average prevalence was reported in the shoulder (table 1). Ninety-one per cent of the players reported some type of overuse injury problem at some point during the season in either 
Table 1 Pain and injury at baseline in \% (number of players)

\begin{tabular}{llc}
\hline Anatomical area & Last season & Baseline \\
\hline Shoulder & $38(53)$ & $20(28)$ \\
Knee & $36(51)$ & $19(26)$ \\
Elbow & $23(32)$ & $9(13)$ \\
Lower back & $26(37)$ & $11(16)$ \\
\hline
\end{tabular}

of the predetermined areas, and nearly half (48\%) reported a substantial problem. Visual inspection of prevalence charts showed the injury prevalence was stable throughout the season for all injury outcomes (tables 2 and 3 ).

\section{DISCUSSION}

The main finding of this study was that, at any given time during the handball season, the average prevalence of all overuse injury problems in any anatomical area was $39 \%$ (95\% CI $29 \%$ to $49 \%$ ). Shoulder problems had the greatest average prevalence, whereas knee problems had the greatest relative burden. These findings suggest that the magnitude of overuse injuries among male junior handball players is high. To our knowledge, this is the first prospective cohort study of the prevalence of overuse injuries among junior elite male handball players.

Our prospective injury data are consistent with previous epidemiological studies among senior male handball players. ${ }^{79} 111214161819$ In particular, studies of senior players have also found a high prevalence of overuse problems in the shoulder, ${ }^{79}{ }^{18}$ knee and low back. ${ }^{9}$ However, we found that the average prevalence of shoulder and knee problems among junior players was $5 \%-10 \%$ lower than has been previously reported among elite senior players. ${ }^{7918}$ Nevertheless, the prevalence in the current study remains high and warrants prevention efforts.

Table 2 Average prevalence of all overuse problems and substantial problems in dominant and non-dominant anatomical areas, \% (95\% Cl)

\begin{tabular}{lcc}
\hline Anatomical area & All problems & $\begin{array}{l}\text { Substantial } \\
\text { problems }\end{array}$ \\
\hline Shoulder combined & $17(16$ to 19$)$ & $7(7$ to 8$)$ \\
\hline Dominant shoulder & $16(14$ to 17$)$ & $7(6$ to 7$)$ \\
\hline Non-dominant shoulder & $3(2$ to 4$)$ & $1(0$ to 1$)$ \\
\hline Elbow combined & $9(8$ to 9$)$ & $1(1$ to 2$)$ \\
\hline Dominant elbow & $7(6$ to 8$)$ & $1(1$ to 2$)$ \\
\hline Non-dominant elbow & $4(3$ to 4$)$ & $0(0$ to 0$)$ \\
\hline Knee combined & $14(13$ to 15$)$ & $5(4$ to 5$)$ \\
\hline Dominant knee & $12(11$ to 13$)$ & $4(4$ to 5$)$ \\
\hline Non-dominant knee & $9(8$ to 10$)$ & $3(2$ to 3$)$ \\
Lower back & $12(11$ to 13$)$ & $3(2$ to 3$)$ \\
\hline All areas & $37(34$ to 40$)$ & $15(14$ to 16$)$ \\
\hline
\end{tabular}

Table 3 Cumulative severity score and relative burden of overuse injuries in all anatomical areas

\begin{tabular}{lcc}
\hline Anatomical area & $\begin{array}{l}\text { Cumulative } \\
\text { severity score }\end{array}$ & $\begin{array}{l}\text { Relative } \\
\text { burden (\%) }\end{array}$ \\
\hline Shoulder combined & 16234 & 33 \\
\hline Dominant shoulder & 14110 & 29 \\
\hline Non-dominant shoulder & 2124 & 4 \\
\hline Elbow combined & 6802 & 14 \\
\hline Dominant elbow & 4846 & 10 \\
\hline Non-dominant elbow & 1976 & 4 \\
Knee combined & 17540 & 36 \\
\hline Dominant knee & 10153 & 21 \\
Non-dominant knee & 7387 & 15 \\
Lower back & 8106 & 17 \\
All areas & 48683 & 100 \\
\hline
\end{tabular}

\section{Methodological considerations}

The main strengths of this study were the use of a sensitive injury registration method to capture the extent of overuse injuries. Previous studies of young handball players have used time loss definition and incidence-based measures, hence underestimated the prevalence of overuse injuries. ${ }^{79}$ Our approach used an all-complaints definition and recorded the consequences of injury beyond time loss, more appropriate for capturing overuse injuries. ${ }^{68}$

Additional strengths of this study included its fullseason duration, its relatively large sample size and the high response rate to the questionnaire. Furthermore, we differentiated between dominant and non-dominant anatomical areas, which can help explain the full burden of overuse injuries among junior players more thoroughly than previous studies.

\section{Limitations}

There are several methodological limitations to consider when interpreting this study's results. First, our injury registration was based only on players' self-assessment of their pain, and its impact on their participation, training volume and sports performance. We did not attempt to confirm specific diagnoses using clinical assessments, which would have strengthened the data. Relying on self-reports meant that we were unable to confirm that the correct anatomical location was assigned, or whether all reported problems were indeed overuse injuries. Although we provided players with detailed definitions, instructions and examples, it is possible that some acute injuries were misclassified as overuse, or that some overuse injuries were not recorded.

A second methodological limitation is that, in using a broad 'all physical complaints' injury definition, we may have classified some cases of 'normal' pain related to athletic participation, such as delayed-onset muscle soreness, as overuse injury. Therefore, to filter out the minor cases with little functional consequences, we also used a substantial overuse injury definition. 
Using this study design, we may not have recorded the full extent of overuse injuries affecting this cohort, as we only recorded injuries in a limited number of predefined anatomical areas. We chose to focus on problem areas previously found to be common sites of overuse injury among senior handball players, ${ }^{9}{ }^{19}$ as well as the elbow, due to reports from coaches, players and clinicians working with handball players. However, other studies have reported anterior tibial pain to be common among junior and senior players, ${ }^{12} 20$ which would have been missed in the current study.

The final limitations of this study were that we only included junior male players, who have previously been found to have a higher injury risk than junior female players, ${ }^{11} 12$ and we did not consider the relationship between training loads and injury. Future studies of junior handball players should address these questions.

\section{Perspective}

The prevalence of overuse injuries among junior male handball players is high, particularly in the shoulder and the knee. Our results reiterate the importance of preventative measures in the sport of handball and shed new light on the burden of overuse injuries among male junior handball players. ${ }^{791214192122}$

A large proportion of overuse injuries lead to reduced handball participation, training volume and performance during a critical developmental period. The development of effective prevention strategies for overuse injuries among junior male handball players should therefore be a priority.

Acknowledgements The authors would like to thank all players and coaches who participated in the study, as well as the medical staff. The Oslo Sports Trauma Research Center has been established at the Norwegian School of Sport Sciences through generous grants from the Royal Norwegian Ministry of Culture, the South-Eastern Norway Regional Health Authority, the IOC, the Norwegian Olympic Committee and Confederation of Sport, and Norsk Tipping AS.

Contributors CA, HS, SHA and LE contributed to project planning. CA and HS contributed to data collection and manuscript preparation. $\mathrm{BC}$ was responsible for data analysis. $\mathrm{BC}$ is responsible for the overall content as the guarantor.

Funding The authors have not declared a specific grant for this research from any funding agency in the public, commercial or not-for-profit sectors.

\section{Competing interests None declared.}

Patient consent Obtained.

Ethics approval Eastern Norway Regional Committee for Research Ethics (2016/934) approved the study. Participation was voluntary and the authors obtained individual written informed consent from players or guardians.

Provenance and peer review Not commissioned; externally peer reviewed. Data sharing statement All data available on request.

Open access This is an Open Access article distributed in accordance with the Creative Commons Attribution Non Commercial (CC BY-NC 4.0) license, which permits others to distribute, remix, adapt, build upon this work non-commercially, and license their derivative works on different terms, provided the original work is properly cited and the use is non-commercial. See: http://creativecommons.org/ licenses/by-nc/4.0/ (c) Article author(s) (or their employer(s) unless otherwise stated in the text of the article) 2018. All rights reserved. No commercial use is permitted unless otherwise expressly granted.

\section{REFERENCES}

1. Engebretsen L, Soligard T, Steffen K, et al. Sports injuries and illnesses during the London Summer Olympic Games 2012. Br J Sports Med 2013;47:407-14.

2. Junge $A$, Engebretsen L, Mountjoy ML, et al. Sports injuries during the Summer Olympic Games 2008. Am J Sports Med 2009;37:2165-72.

3. Junge A, Langevoort G, Pipe A, et al. Injuries in team sport tournaments during the 2004 Olympic Games. Am J Sports Med 2006;34:565-76.

4. Bahr R. No injuries, but plenty of pain? On the methodology for recording overuse symptoms in sports. Br J Sports Med 2009;43:966-72.

5. Bahr R. International Olympic Committee. The IOC manual of sports injuries : an illustrated guide to the management of injuries in physical activity. Chichester, West Sussex, UK ; Hoboken, NJ: WileyBlackwell, 2012.

6. Clarsen B, Myklebust G, Bahr R. Development and validation of a new method for the registration of overuse injuries in sports injury epidemiology: the Oslo Sports Trauma Research Centre (OSTRC) overuse injury questionnaire. Br J Sports Med 2013;47:495-502.

7. Clarsen B, Bahr R, Andersson SH, et al. Reduced glenohumeral rotation, external rotation weakness and scapular dyskinesis are risk factors for shoulder injuries among elite male handball players: a prospective cohort study. Br J Sports Med 2014;48:1327-33.

8. Clarsen B, Rønsen O, Myklebust G, et al. The Oslo Sports Trauma Research Center questionnaire on health problems: a new approach to prospective monitoring of illness and injury in elite athletes. $\mathrm{Br} \mathrm{J}$ Sports Med 2014;48:754-60.

9. Clarsen B, Bahr R, Heymans MW, et al. The prevalence and impact of overuse injuries in five Norwegian sports: Application of a new surveillance method. Scand J Med Sci Sports 2015;25:323-30.

10. Soligard T, Schwellnus M, Alonso JM, et al. How much is too much? (Part 1) International Olympic Committee consensus statement on load in sport and risk of injury. Br J Sports Med 2016;50:1030-41.

11. Olsen OE, Myklebust G, Engebretsen L, et al. Injury pattern in youth team handball: a comparison of two prospective registration methods. Scand J Med Sci Sports 2006;16:426-32.

12. Moller M, Attermann J, Myklebust G, et al. Injury risk in Danish youth and senior elite handball using a new SMS text messages approach. Br J Sports Med 2012;46:531-7.

13. DiFiori JP, Benjamin HJ, Brenner J, et al. Overuse injuries and burnout in youth sports: a position statement from the American Medical Society for Sports Medicine. Clin J Sport Med 2014;24:3-20.

14. Wedderkopp N, Kaltoft M, Lundgaard B, et al. Injuries in young female players in European team handball. Scand J Med Sci Sports 1997;7:342-7.

15. Wedderkopp N, Kaltoft M, Lundgaard B, et al. Prevention of injuries in young female players in European team handball. A prospective intervention study. Scand J Med Sci Sports 1999;9:41-7.

16. Andersen CA, Clarsen B, Johansen TV, et al. High prevalence of overuse injury among iron-distance triathletes. Br J Sports Med 2013;47:857-61.

17. Bahr R, Clarsen B, Ekstrand J. Why we should focus on the burden of injuries and illnesses, not just their incidence. Br J Sports Med 2017:bjsports-2017-098160.

18. Andersson SH, Bahr R, Clarsen B, et al. Preventing overuse shoulder injuries among throwing athletes: a cluster-randomised controlled trial in 660 elite handball players. Br J Sports Med 2017;51:10731080.

19. Myklebust G, Hasslan L, Bahr R, et al. High prevalence of shoulder pain among elite Norwegian female handball players. Scand J Med Sci Sports 2013;23:288-94.

20. Pasanen K, Parkkari J, Kannus $P$, et al. Injury risk in female floorball: a prospective one-season follow-up. Scand J Med Sci Sports 2008;18:49-54.

21. Seil R, Rupp S, Tempelhof S, et al. Sports injuries in team handball. A one-year prospective study of sixteen men's senior teams of a superior nonprofessional level. Am J Sports Med 1998;26:681-7.

22. Møller M, Nielsen RO, Attermann J, et al. Handball load and shoulder injury rate: a 31-week cohort study of 679 elite youth handball players. Br J Sports Med 2017;51:231-7. 